\title{
Mothers' utilization and associated factors in preconception care in northern Ethiopia: a community based cross sectional study
}

\author{
Tsrity Tadese Asresu ${ }^{1 *}\left(\mathbb{D}\right.$, Desta Hailu², Berhe Girmay², Mulugeta Woldu Abrha ${ }^{3}$ and \\ Haftom Gebrehiwot Weldearegay ${ }^{4}$
}

\begin{abstract}
Background: Adverse pregnancy outcomes remain a prevalent health problem in Ethiopia. Mothers' use of preconception care service has the potential to avert many of the adverse outcomes. However, the use of this service and its determinants is not well investigated. Therefore, this study was conducted to assess the utilization and determinants of preconception care among recently delivered mothers.

Methods: A community based cross-sectional design was conducted among 564 recently delivered mothers in Mekelle City, Northern Ethiopia. A multi stage cluster sampling technique was employed. Data was collected using a pre-tested, structured interviewer questionnaire and was entered in to Epi-Info ${ }^{\mathrm{TM}}$ Version 7 and analyzed using SPSS ${ }^{\mathrm{TM}}$ Version 20.0. Descriptive, bivariable and multivariable logistic regression was used to identify the association.

Results: This study revealed that, 102(18.2\%) of the mothers had utilized preconception care. Mothers' knowledge on preconception care (AOR: 2.21; 95\% Cl: 1.03, 4.73), prior experience of adverse birth outcomes (AOR: 5.10; 95\% Cl: $2.31,11.24$ ), history of chronic health problems (AOR: 5.69; $95 \%$ Cl: 2.06, 15.72), husband's support (AOR: 13.84; $95 \%$ Cl: $6.02,31.79$ ), and challenges in accessing a health facility (AOR: $0.24 ; 95 \% \mathrm{Cl}: 0.16,0.48$ ) were significantly associated with preconception care service utilization.

Conclusion: Mothers' utilization of preconception care is low. Mothers knowledge on preconception care, experience of adverse birth outcome, having chronic health problems and husband support increases utilization of preconception care. However, mothers who experienced challenges in visiting a health facility showed decrease preconception care utilization. Therefore, increased efforts are need in terms of advocating for involvement of husband's and awareness creation respecting preconception care services for all women.
\end{abstract}

Keywords: Preconception care, Adverse birth outcomes, Mekelle City, Ethiopia

\section{Background}

Care given to a couple to ensure they are in good health before they conceive a child is an essential component to optimize the health and development of future offspring. Preconception care (PCC) improves the health of women and men while reducing the chances that their children will experience: prematurity, low birth weight, birth defects or other birth-related conditions that could hinder optimal child development [1,2]. Preconception care is a critical component of health which includes the

\footnotetext{
* Correspondence: tsritytadese15@gmail.com

${ }^{1}$ Mekelle University, College of Health Sciences, Mekelle, Ethiopia

Full list of author information is available at the end of the article
}

provision of biomedical, behavioral and social health interventions to women of reproductive age and couples before they conceive $[3,4]$.

The World Health Organization has recommended a package of interventions for PCC including maternal nutrition such as micronutrient supplementation (iron, folic acids and others), vaccination, cessation of tobacco and excessive alcohol use, prevention of interpersonal violence, sexuality education, protection from environmental hazards, genetic counseling, and support for mental health. Adolescence is a prime - though not the only - window of opportunity to deliver these interventions $[4,5]$.

(c) The Author(s). 2019 Open Access This article is distributed under the terms of the Creative Commons Attribution 4.0 International License (http://creativecommons.org/licenses/by/4.0/), which permits unrestricted use, distribution, and reproduction in any medium, provided you give appropriate credit to the original author(s) and the source, provide a link to the Creative Commons license, and indicate if changes were made. The Creative Commons Public Domain Dedication waiver (http://creativecommons.org/publicdomain/zero/1.0/) applies to the data made available in this article, unless otherwise stated. 
This risk of maternal and infant mortality and pregnancyrelated complications can be reduced by increasing access to quality preconception (before pregnancy) and interconception (between pregnancies) care [6]. Preconception care has a positive impact on reduction in mortality and decrease the risk of adverse health effects for the woman, fetus, and neonate by optimizing the woman's health and knowledge before planning and conceiving a pregnancy $[6,7]$. Moreover, Interventions before pregnancy can increase the health and well-being of adolescents, adult women and men, and improve subsequent pregnancy and child health outcomes $[8,9]$. This evidence indicated that, PCC is one of the evidence-based health promotion interventions to prevent adverse pregnancy outcomes. Nevertheless, it is one of the missing elements within the continuum of maternal and child health care [10, 11].

Although the government of Ethiopia has been working to improve coverage and access to institutional delivery and postpartum care over the past couple of decades, adverse pregnancy outcomes, specifically neural tube related defects such as anencephaly, spinal bifida, and encephalocoele, are increasing at an alarming rate. Furthermore, PCC service is provided in both hospitals and health centers in Ethiopia. However, there are concerns about standardize and regular PCC service provided for all reproductive age group mothers $[8,12]$.

To date, a limited number of studies have considered on factors associated with the mother's utilization of PCC service in Ethiopia. Therefore, this study sought to determine the prevalence of mothers' utilization and associated factors of PCC and will contribute to the design of effective preventive strategies to tackle the rising burden of adverse pregnancy and birth outcomes.

\section{Methods}

\section{Study setting and participants}

A community based cross-sectional study design was conducted between March 15th and April 30th, 2018 in Mekelle City, which is the capital city of Tigray Regional State, Ethiopia. Mekelle city is divided into AddiHak'i, Ayder, Haddinet, Hawelti, Qedamay Weyyane, Kwiha, and Semien sub-cities and also subdivided into 33 Tabias. ${ }^{1}$ According to the 2017 report, a total of 412,938 people reside in Mekelle city with $23.48 \%$ percent being of the female reproductive age group (i.e., 15-49 years). The source of population were all delivered mothers in Mekelle Citywith the study population comprised of all delivered mothers in selected ketenas ${ }^{2}$ of Mekelle City.

\footnotetext{
${ }^{1}$ Tabia: The unit of administration consists of 3 and above ketena or $10-15,000$ population.

${ }^{2}$ Ketena: The smallest unit of administration consists of a minimum of 4000 population, but sometimes depends on geographical location.
}

\section{Sampling technique and procedure}

A sample of 564 participants were selected using the single population proportion formula with the following assumptions: proportion (P) of PCC experience which is $38.2 \%$ conducted in Ethiopia [12], a confidence level (CI) of 95\%, marginal error (d) 5, 5\% non-response and considering a design effect of 1.5. A multi-stage cluster sampling technique was employed. In the first stage, three sub-cities were selected randomly and from the fourteen tabias of these selected sub-cities. In the second stage, five tabias of the 14 were chosen and then two ketenas from each of the tabias were select by simple random sampling (SRS) technique.

\section{Data collection instrument and quality management}

Data was collected using a structured pre-tested questionnaire through a face-to-face interview. The questionnaire was informed by reviewed literature emanating from the relevant research area. Prior to data collection, validity and reliability testing of the instrument was undertaken. To examine content validity, a panel of experts was asked to review and refine each item in the instrument. This panel was composed of three senior midwives and/or nurses, one obstetrician, and two researchers in the field of reproductive health. The items had strong internal consistency $(\alpha=$ $0.76)$ among a sub-sample of participants $(n=30)$. Data quality was assured by trained Bachelor of Science Degree holders who were fluent in the local language; Tigrigna.

Daily supervision, spot checking, and review of the completed questionnaires was conducted by the research assistants.

\section{Variables}

Utilization of PCC was the outcome of interest and the independent variables were demographic characteristics, obstetric and reproductive health factors, knowledge, as well as family and health care system factors.

\section{Statistical analyses}

Data were coded and entered into EPi-Info ${ }^{\text {TM }}$ Version 7 software. Descriptive analysis was done. Binary logistic regression and multivariable logistic regression models were performed to obtain the crude and adjusted odds ratios for the outcome variable, using the SPSS $20^{\text {ma }}$ - statistical package. Statistical significance was set at $p<0.05$.

\section{Ethical consideration}

Ethical clearance was obtained from Mekelle University, College of Health Sciences - Ethical Review Board. In addition, an official letter of cooperation was granted by the Tigray Regional Health Bureau and administrative offices of Mekelle City. The purpose of the study was explained to the study participants and written informed consent was obtained. Participation was on a voluntary basis after written consent and confidentiality were secured. 
Table 1 Socio-demographic characteristics of participants in North Ethiopia, $2018(N=561)$

\begin{tabular}{|c|c|c|}
\hline Variable & Frequency & Percent (\%) \\
\hline \multicolumn{3}{|l|}{ Age } \\
\hline $15-24$ & 88 & 15.7 \\
\hline $25-34$ & 277 & 49.4 \\
\hline $35-45$ & 196 & 34.9 \\
\hline \multicolumn{3}{|l|}{ Mother's education } \\
\hline No formal education & 74 & 13.2 \\
\hline Can read and write & 73 & 13.0 \\
\hline Elementary school & 127 & 22.6 \\
\hline Secondary school & 191 & 34.0 \\
\hline College/university & 96 & 17.1 \\
\hline \multicolumn{3}{|l|}{ Marital status } \\
\hline Married & 438 & 78.1 \\
\hline Single/never married & 62 & 11.1 \\
\hline Divorced & 53 & 9.4 \\
\hline Widowed & 8 & 1.4 \\
\hline \multicolumn{3}{|l|}{ Occupation } \\
\hline Housewife & 232 & 41.4 \\
\hline Daily worker & 94 & 16.8 \\
\hline Government employee & 104 & 18.5 \\
\hline Private business & 129 & 23.0 \\
\hline Student & 2 & 0.4 \\
\hline \multicolumn{3}{|l|}{ Religion } \\
\hline Orthodox & 508 & 90.6 \\
\hline Muslim & 42 & 7.5 \\
\hline Others $^{a}$ & 11 & 2.0 \\
\hline \multicolumn{3}{|l|}{ Ethnicity } \\
\hline Tigray & 539 & 96.1 \\
\hline Amhara & 13 & 2.3 \\
\hline Afar & 9 & 1.6 \\
\hline \multicolumn{3}{|c|}{ Income of respondents in ETB } \\
\hline Less than 500 & 132 & 23.5 \\
\hline $501-1000$ & 207 & 36.9 \\
\hline $1001-2000$ & 151 & 26.9 \\
\hline 2001 and above & 71 & 12.7 \\
\hline \multicolumn{3}{|c|}{ Time spent to reach health facility } \\
\hline Less than $30 \mathrm{~min}$ & 322 & 57.4 \\
\hline $30 \mathrm{~min}$ and above & 239 & 42.6 \\
\hline \multicolumn{3}{|c|}{ Means of transport to reach facility } \\
\hline Foot & 303 & 54.0 \\
\hline Public transport & 187 & 33.3 \\
\hline Private transport & 71 & 12.7 \\
\hline
\end{tabular}

${ }^{\mathrm{a}}$ Other religions $=$ Catholic and Protestant
Table 2 Obstetric and Reproductive Health Characteristics, North Ethiopia, $2018(N=561)$

\begin{tabular}{lll}
\hline Variable & Frequency & Percent \\
\hline Gravidity & & \\
1 Pregnancy & 113 & 20.1 \\
2-4 Pregnancies & 379 & 67.6 \\
Z5 Pregnancies & 69 & 12.3 \\
Parity & & \\
$\quad$ Primipara (1 delivery) & 138 & 24.6 \\
Multipara (2 \& above delivery) & 423 & 75.4 \\
Previous use of family planning & & \\
$\quad$ Yes & 341 & 60.8 \\
$\quad$ No & 220 & 39.2 \\
Previous adverse pregnancy outcome & & 21.0 \\
Yes & 118 & 79.0 \\
No & 443 &
\end{tabular}

Type of adverse pregnancy outcome $(n=118)$ (Multiple responses)

Congenital anomalies $\quad 23 \quad 19.5$

Low birth weight $\quad 17 \quad 14.4$

$\begin{array}{lll}\text { Preterm } & 10 & 8.5\end{array}$

$\begin{array}{lll}\text { Abortion } & 67 & 56.8\end{array}$

Still birth $\quad 22 \quad 18.6$

$\begin{array}{lll}\text { Neonatal death } & 7 & 5.9\end{array}$

Infection 13

Place where PCC was received

$\begin{array}{lll}\text { Hospital } & 62 & 60.8 \\ \text { Health center } & 24 & 23.5 \\ \text { Private clinic } & 16 & 15.7\end{array}$

Having cultural factor ${ }^{a}$

$\begin{array}{lll}\text { Yes } & 33 & 5.9\end{array}$

$\begin{array}{lll}\text { No } & 528 & 94.1\end{array}$

Husband support for PCC

$\begin{array}{lll}\text { Yes } & 159 & 28.3\end{array}$

$\begin{array}{lll}\text { No } & 402 & 71.7\end{array}$

Joint plan discussion with partner

$\begin{array}{lll}\text { Yes } & 167 & 29.8\end{array}$

$\begin{array}{lll}\text { No } & 394 & 70.2\end{array}$

Chronic health problem

$\begin{array}{lll}\text { Yes } & 39 & 7.0 \\ \text { No } & 522 & 93.0\end{array}$

Type of chronic health problem $(n=39)$ (Multiple responses)

$\begin{array}{lll}\text { HIV/AIDS } & 14 & 35.9 \\ \text { HTN } & 14 & 35.9 \\ \text { Diabetes mellitus } & 5 & 12.8 \\ \text { Others }^{\text {b }} & 8 & 20.5\end{array}$

${ }^{\mathrm{a}}$ Other chronic health problem: epilepsy, tuberculosis and anemia ${ }^{b}$ Cultural factor: use traditional medicine, holly water and autonomy deficit to decide 


\section{Results}

\section{Socio-demographic characteristics}

A total of 561 mothers who delivered within the last year (12 months or less) were included in the study with a response rate of $99.5 \%$. Of the 561 participants, about half of the mothers $(277 ; 49.4 \%)$ were within the age group 25-34 years and ranged from 18 to 43 years. The mean age of the participants was 31.22 years $( \pm 6.04)$.

Majority of study participants $(536 ; 96.1 \%)$ were from Tigray ethnic group, and 232(41.4\%) were house wives by occupation. More than three-quarters $(438 ; 78.1 \%)$ of the participants were married, with over 90\% (580) belonged to the Orthodox Christian religion and one third (191; 34\%) had secondary school education (Table 1).

\section{Obstetrics and reproductive health characteristics}

Assessment of obstetric and reproductive health characteristics revealed that about $370(67.6 \%)$ participants had between two to four pregnancies. Concerning parity, three-quarters $(423 ; 75.4 \%)$ of participants were multipara. Six out of ten $(341 ; 60.8 \%)$ respondents had a history of family planning use. On the subject of previous adverse birth outcomes, $118(21 \%)$ had a history of one or more adverse birth outcomes. Of those, who had adverse birth outcome, 67(56.8\%), 22(18.6) and 23(19.5\%) of participants reported that they had experienced abortion, still birth, and congenital malformations respectively.

Regarding access to PCC, six out of ten mothers $62(60.8 \%)$ received the care from hospital. Thirty-nine
(7\%) of respondents had a chronic health problem. With respect to husband/partner support on PCC, 159 (28.3\%) of participants had a partner support to uptake preconception care and $167(29.8 \%)$ had a joint plan discussion with their partner about PCC (Table 2).

\section{Utilization of preconception care}

Among the 561 participants, 102(18.2\%) mothers had utilized at least one component of the World Health Organization package of PCC services before their last baby. The most commonly utilized component of PCC in this study was micronutrient supplementation (i.e., iron, folic acid) $88(86.3 \%)$ whereas the least utilized was optimizing psychological health (5.9\%) (Fig. 1).

\section{Predictors for the utilization of preconception care}

In this study, results of the bivariable logistic regression showed that mothers' age, level of education, monthly income, history of family planning use, experience of adverse birth outcome, joint discussion plan with partner, chronic health problem, challenge to visit heath facility, husband support and knowledge on preconception care were associated with utilization of PCC.

Through multivariable logistic regression, a history of adverse birth outcome, chronic health problem, husband support, challenge to access health facility, and knowledge on preconception care was found to have significant statistical association with utilization of PCC.

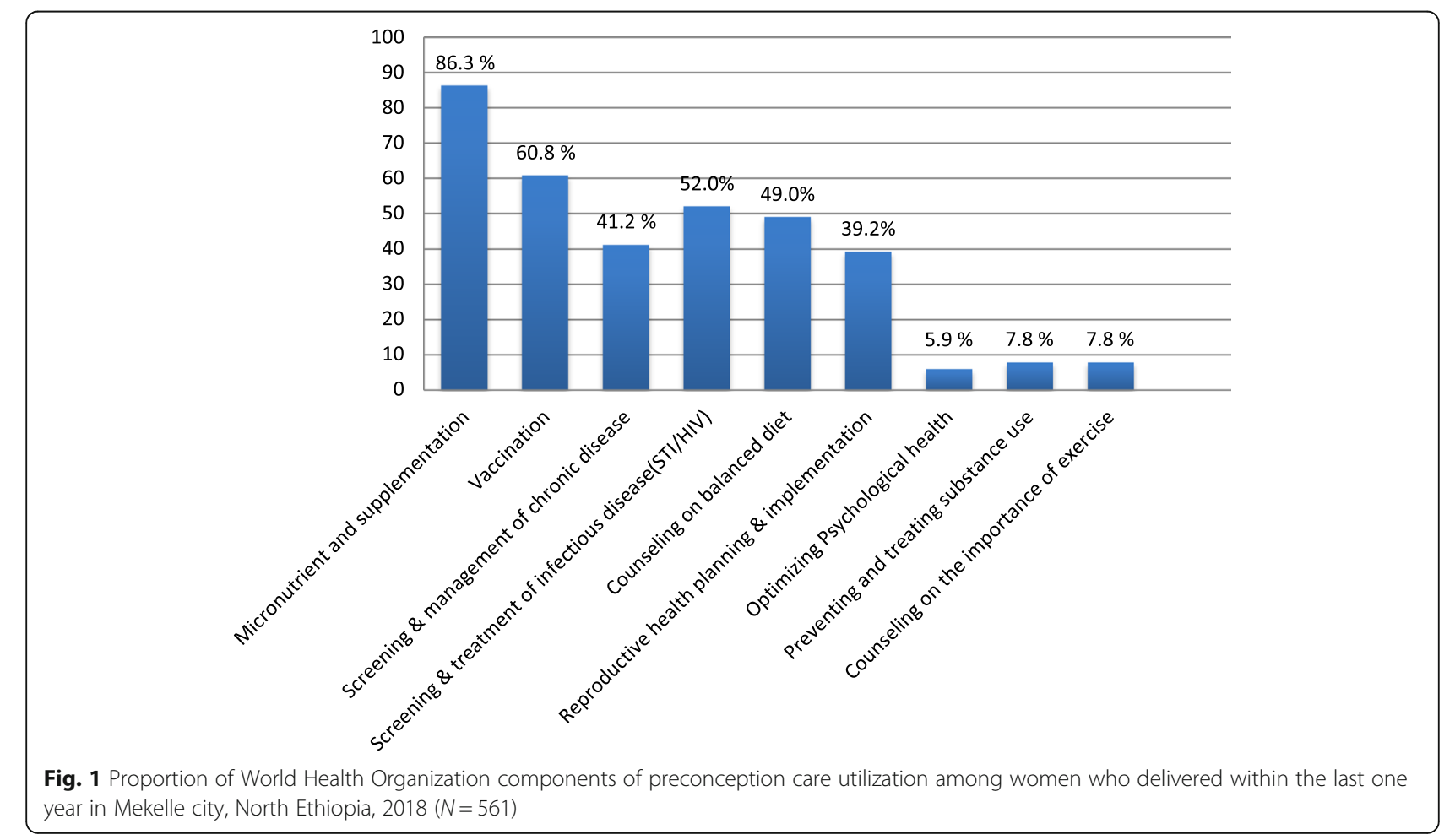


Mothers who were knowledgeable about PCC had two times higher odds of service utilization when compared to their counter parts (AOR: 2.21; 95\% CI: 1.03, 4.73).

The odds of PCC utilization were five times higher among mothers who had a history of adverse pregnancy outcomes compared those who did not experience an adverse event (AOR:5.1; 95\% CI:2.31,11.24).
In addition, mothers who had chronic health problems were nearly six times more likely to utilize PCC compared to their non-chronic disease afflicted counterparts (AOR: 5.69; 95\% CI: 2.06, 15.72). This study revealed that husband/partner support has a significant effect on the PCC service utilization. Mothers who received support from their husbands were nearly 14 times more

Table 3 Association between different variables and preconception care among women who delivered within the last one year in Mekelle city, North Ethiopia, 2018 ( $N=561)$

\begin{tabular}{|c|c|c|c|c|}
\hline \multirow[t]{2}{*}{ Variable } & \multicolumn{2}{|c|}{ Preconception Care Utilization } & \multicolumn{2}{|c|}{ Odds Ratio and 95\% Cl } \\
\hline & Utilized (\%) & Not utilized (\%) & Crude & Adjusted \\
\hline \multicolumn{5}{|l|}{ Age (years) } \\
\hline $15-24$ & $22(25.0 \%)$ & $66(75.0 \%)$ & 1 & 1 \\
\hline $25-34$ & $58(20.9 \%)$ & 219(79.1\%) & $0.79(0.45-1.39)$ & $1.23(0.50-3.04)$ \\
\hline $35-45$ & $22(11.2 \%)$ & 174(88.8\%) & $0.37(0.19-0.73)^{*}$ & 1.34(0.42-4.24) \\
\hline \multicolumn{5}{|l|}{ Mother's education } \\
\hline No education & $26(17.7 \%)$ & $121(82.3 \%)$ & 1 & 1 \\
\hline Primary education & $11(8.7 \%)$ & 116(91.3\%) & $0.44(0.21-0.93)^{*}$ & $0.59(0.20-1.70)$ \\
\hline Secondary education & $37(19.4 \%)$ & 154(80.6\%) & $1.12(1.01-1.95)^{*}$ & $1.26(0.51-3.13)$ \\
\hline More than secondary education & $28(29.2 \%)$ & $68(70.8 \%)$ & $1.92(1.04-3.53)^{*}$ & $1.24(0.45-3.43)$ \\
\hline \multicolumn{5}{|l|}{ Household income (ETB) } \\
\hline Less than 500 & $36(27.3 \%)$ & $96(72.7 \%)$ & 1 & 1 \\
\hline $501-1000$ & $25(12.1 \%)$ & 182(87.9\%) & $0.37(0.21-0.65)^{* *}$ & $0.46(0.19-1.06)$ \\
\hline $1001-2000$ & $25(16.6 \%)$ & $126(83.4 \%)$ & $0.53(0.29-0.94)^{*}$ & $0.61(0.25-1.52)$ \\
\hline Above 2000 & $16(22.5 \%)$ & $55(77.5 \%)$ & $0.78(0.4-1.53)$ & $0.70(0.25-1.94)$ \\
\hline \multicolumn{5}{|l|}{ Previous family planning use } \\
\hline No & $25(11.4 \%)$ & 195(88.6\%) & 1 & 1 \\
\hline Yes & $77(22.6 \%)$ & $264(77.4 \%)$ & $2.28(1.39-3.71)^{* *}$ & 1.55(0.74-3.23) \\
\hline \multicolumn{5}{|l|}{ Previous adverse birth outcome } \\
\hline No & $62(14.0 \%)$ & $381(86.0 \%)$ & 1 & 1 \\
\hline Yes & $40(33.9 \%)$ & $78(66.1 \%)$ & $3.15(1.98-5.02)^{* *}$ & $5.10(2.31-11.24)^{* *}$ \\
\hline \multicolumn{5}{|c|}{ Joint plan discussion with partner on preconception care } \\
\hline No & $23(5.8 \%)$ & $371(94.2 \%)$ & 1 & 1 \\
\hline Yes & $79(47.3 \%)$ & $88(52.7 \%)$ & $14.48(8.62-24.34)^{* *}$ & $2.05(0.88-4.78)$ \\
\hline \multicolumn{5}{|l|}{ Having any chronic health problem } \\
\hline No & $77(14.8 \%)$ & $445(85.2 \%)$ & 1 & 1 \\
\hline Yes & $25(64.1 \%)$ & 14(35.9\%) & $10.32(5.14-20.73)^{* *}$ & $5.69(2.06-15.72)^{*}$ \\
\hline \multicolumn{5}{|c|}{ Having any challenge to access health facility } \\
\hline No & $82(35.5 \%)$ & $149(64.5 \%)$ & 1 & 1 \\
\hline Yes & $20(6.1 \%)$ & 310(93.9\%) & $0.11(0.07-0.2)^{* *}$ & $0.24(0.16-0.48)^{* *}$ \\
\hline \multicolumn{5}{|l|}{ Having husband/partner support } \\
\hline No & $17(4.2 \%)$ & $385(95.8 \%)$ & 1 & 1 \\
\hline Yes & $85(53.5 \%)$ & $74(46.5 \%)$ & $26.0(14.61-46.33)^{* *}$ & $13.84(6.02-31.79)^{* *}$ \\
\hline \multicolumn{5}{|l|}{ Knowledge index on PCC } \\
\hline Not knowledgeable & $56(11.6 \%)$ & $428(88.4 \%)$ & 1 & 1 \\
\hline Knowledgeable & $46(59.7 \%)$ & $31(40.3 \%)$ & $11.34(6.65-19.34)^{* *}$ & $2.21(1.03-4.73)^{* *}$ \\
\hline
\end{tabular}

${ }^{*} P$-value $<0.05 ;{ }^{*} P$-Value $<0.001$ 
likely to utilize PCC than participants who did not have the support of their husband (AOR: 13.84;95\% CI: 6.02, 31.79). However, mothers who had any challenges in visiting health facilities were $76 \%$ less likely to utilize PCC than mothers who had no such challenge (AOR: 0.24; 95\% CI: 0.16, 0.48) (Table 3).

\section{Discussion}

Understanding of PCC is critical for many Sub-Saharan African countries, such as Ethiopia, where maternal and perinatal mortality remains alarmingly high. This community based cross-sectional study identified factors influencing PCC utilization among mothers who gave birth within the last one year in Mekelle City, north Ethiopia.

The findings of this study showed that 102(18.2\%) of the mothers had utilized PCCS services. This is lower than previous findings in Ethiopia [12], China [13], and Los Angeles [14]. This discrepancy might be due to the difference in access to information, socioeconomic status, and the quality of health care delivery system. However, PCC utilization is higher than a study conducted in Debremarkos town, Ethiopia where only $8.4 \%$ of the pregnant mothers reported using PCC [15]. This variability may be related to differences in the study population's level of education, culture, and the study setting.

Regarding the predictors, this study revealed that knowledge of mothers were associated with PCC utilization, Which was in line with the findings reported from Debremarkos, Ethiopia [15], Oromia, Ethiopia [12], China [13], and Philadelphia [16]. This might relate to information leading to knowing details about the service rather obligations to utilize the service. This suggests that it is evident that knowledge was related to the level of practices or utilization of the services.

According to the current study, husband/partner support has a significant effect on the service utilization of PCC. This finding is consistent with studies done in Ethiopia (Debremarkos) [15], Ethiopia (Oromia) [12] and China [13] which found that the participants who had support from their husbands towards PCC showed increased compliance. This may be due to having reproductive health policies including male engagement strategies promoting maternal and child health care service.

Mothers who had a history of adverse birth outcomes were positively associated with PCC utilization, which was also seen in a study done in Los Angeles [14] indicating previous adverse infant outcomes being associated with increased odds of having utilized PCC in the most recent pregnancy. Potentially mothers' who had an experience of adverse birth outcomes were more conscious and PCC compliant in their subsequent pregnancies.

Finally, this study noted that PCC utilization was negatively associated with mothers who had challenges to access health facilities. Similarly, studies from China [13], and
Sudan [17] showed that having challenges to access/visit health facilities was positively associated with mothers' poor service utilization. Challenges such as lack of finances, unplanned pregnancies, and poor quality of care services are potential contributory barriers to mothers' lack of uptake of PCC services.

\section{Conclusions}

This study found that PCC is low in the select Ethiopian population. Factors which increased utilization of PCC include more health literate mothers, prior adverse birth outcomes, pre-existing chronic health conditions, and husband/partner support. Conversely, barriers to access health care facilities were found to contribute to reduced utilization of PCC.

These findings may inform future scale up of PCC and strengthen PCC units to meet the pressing needs of this population. Consideration of barrier-free (i.e., cost reduced) PCC services and development (or adoption) of evidencebased guidelines to enhance PCC may catalyze such efforts. Further inclusion of male partners needs to be promoted.

It is recommended that mixed methods research, program evaluations, and longitudinal research efforts be undertaken to explore and address the imperative for PCC.

\section{Abbreviation}

PCC: Preconception care services

\section{Acknowledgements}

We would like to extend our gratefulness to Mekelle University for allowing us to conduct this study. Our appreciation and thanks is forwarded to all research assistants and study participants for their genuine participation in this survey. It is also a great honor to thank Professor Pammla Petrucka and Mr. Hayelom Gebrekirstos for reviewing standard of English of the manuscript.

\section{Authors' contributions}

TAT: Conceived and designed the study, performed analysis and interpretation of the data. DH: Participated in the design, developing methods and critically reviewed the manuscript. BG: Participated in the study design, data analysis, interpretation and draft manuscript. MAW: Critically evaluated and made progressive suggestions throughout the study. HWG: Participated in the data analysis, interpretation, and critically revise the manuscript. All authors have read and approved the manuscript.

\section{Funding}

A graduate research grant was provided Mekelle University. The funder had no role in study design, data collection, analysis and interpretation, decision to publish, or preparation of the manuscript.

\section{Availability of data and materials}

The datasets used and/or analyzed during the current study is available from the corresponding author on request.

\section{Ethics approval and consent to participate}

The study was approved by Mekelle University Institutional Review Board (ERC1305/2018). Written informed consent was obtained from each study participant and for those participants under the age of 18 years written informed consent was received from their legal guardians.

Consent for publication

Not applicable for this publication.

Competing interests

The authors declare that they have no competing interests. 


\section{Author details}

${ }^{1}$ Mekelle University, College of Health Sciences, Mekelle, Ethiopia. ${ }^{2}$ Mekelle University, College of Health Sciences, School of Nursing, Mekelle, Ethiopia. ${ }^{3}$ Tigray Health Research Institute, Mekelle, Ethiopia. ${ }^{4}$ Department of Midwifery, Mekelle University, College of Health Sciences, Mekelle, Ethiopia.

Received: 17 July 2018 Accepted: 26 August 2019

Published online: 11 October 2019

\section{References}

1. Moos MK, Dunlop AL, Jack BW, Nelson L, Coonrod DV, Long R, Boggess K, Gardiner PM. Healthier women, healthier reproductive outcomes: recommendations for the routine care of all women of reproductive age. Am J Obstet Gynecol. 2008;199:S280-9. https://doi.org/10.1016/j.ajog.2008.08.060.

2. Williams L, Zapata LB, D'Angelo DV, et al. Associations between preconception counseling and maternal behaviors before and during pregnancy. Matern Child Health J. 2012;16:1854.

3. World Health Organization. Preconception care to reduce maternal and childhood mortality and morbidity meeting report and packages of interventions, 2012.

4. World Health Organization. Policy Brief: Preconception health -maximizing the gains of maternal, child health. 2013.

5. Charafeddine L, Rafei R, Azizi S, Sinno D, Alamiddine K, Howson CP, et al. Improving awareness of preconception health among adolescents: experience of a school-based intervention in Lebanon. BMC Public Health. 2014;14:774.

6. Demisse T, Aliyu S, Kitila S, et' a. Utilization of preconception care and associated factors among reproductive age group women in Debre Birhan town, north Shewa, Ethiopia. Reprod Health. 2019;16(96). https://doi.org/1 0.1186/s12978-019-0758-X.

7. Kassa A, Yohannes Z. Women's knowledge and associated factors on preconception care at public health institution in Hawassa City, South Ethiopia. BMC Res Notes. 2018;11(841). https:/doi.org/10.1186/s13104-018-3951-z.

8. Johnson K. Addressing women's health needs and improving birth outcomes: results from a peer-to-peer state Medicaid learning project. He Commonwealth Fund. 2012;21:1-20.

9. Roshina AK. Pre conception health and counseling-are we doing enough? Developments Clin Med Pathol. 2018;1:3.

10. Olowokere AE, Komolafe A, Owofadeju C. Awareness, knowledge and uptake of preconception care among women in Ife central local government area of Osun state, Nigeria. J Comm Med Prim Health Care. 2015;27:83-92.

11. Kassa A, Human SP, Gemeda H. Knowledge of preconception care among health care providers working in public health institutions in Hawassa, Ethiopia. PLoSONE. 2018;13(10):e0204415. https://doi.org/10.1371/journal.pone.0204415.

12. Gezahegn, A. Assessment knowledge and experience of preconception care among pregnant mothers attending antenatal care in west Shoa zone, public health centers, Ethiopia. Unpublished thesis. Addis Ababa Uuniversity, College of Health Sciences. School of Allied Health Sciences, department of midwifery and nursing, Addis Ababa, Ethiopia, 2016. Accessed on February 19, 2019 at: http://etd.aau.edu.et/bitstream/handle/123456789/6703/Andualem\%2 OGezahegn.pdf?sequence $=1$ \&isAllowed $=\mathrm{y}$.

13. Yan D, Xiao-Tian L, Fei X, Yu-Lin Y. Survey on the implementation of preconception Care in Shanghai, China. Paediatr Perinat Epidemiol. 2015;29:492-500.

14. Batra P, Higgins C, Chao SM. Previous adverse infant outcomes as predictors of preconception care use: an analysis of the 2010 and 2012 Los Angeles mommy and baby (LAMB) surveys. Matern Child Health. 2016;20(6):1170-7.

15. Tagele A. Knowledge, practice and associated factors of preconception care service among pregnant women attending antenatal care in governmental health facilities, Debremarkos town, Northwest Ethiopia: unpublished thesis. 2015.

16. Mazza D, Chapman A. Improving the uptake of preconception care and periconceptional folate supplementation: what do women think? BMC Public Health. 2010;10(786). https://doi.org/10.1186/1471-2458-10-786.

17. Gautam P, Dhakal R. Knowledge on preconception care among reproductive age women. Saudi J Med Pharm Sci. 2016;2(1):1-6

\section{Publisher's Note}

Springer Nature remains neutral with regard to jurisdictional claims in published maps and institutional affiliations.

Ready to submit your research? Choose BMC and benefit from:

- fast, convenient online submission

- thorough peer review by experienced researchers in your field

- rapid publication on acceptance

- support for research data, including large and complex data types

- gold Open Access which fosters wider collaboration and increased citations

- maximum visibility for your research: over $100 \mathrm{M}$ website views per year

At BMC, research is always in progress.

Learn more biomedcentral.com/submissions 